$88(2)$

PREPARED FOR THE U.S. DEPARTMENT OF ENERGY, UNDER CONTRACT DE-AC02-76-CHO-3073

PL-2807

$-420,426,427$

\title{
SPITZER OR NEOLASSICAL RESISTIVITY: A COMPARISON BETWEEN MEASURED AND MODEL POLOIDAL FIELD PROFILES ON PBX-M
}

BY

S.M. KAYE, F.M. LEVINTON, R. HATCHER, R. KAITA, C. KESSEL, B. LEBLANC, D.C. MCCUNE AND S. PAUL

January 1992

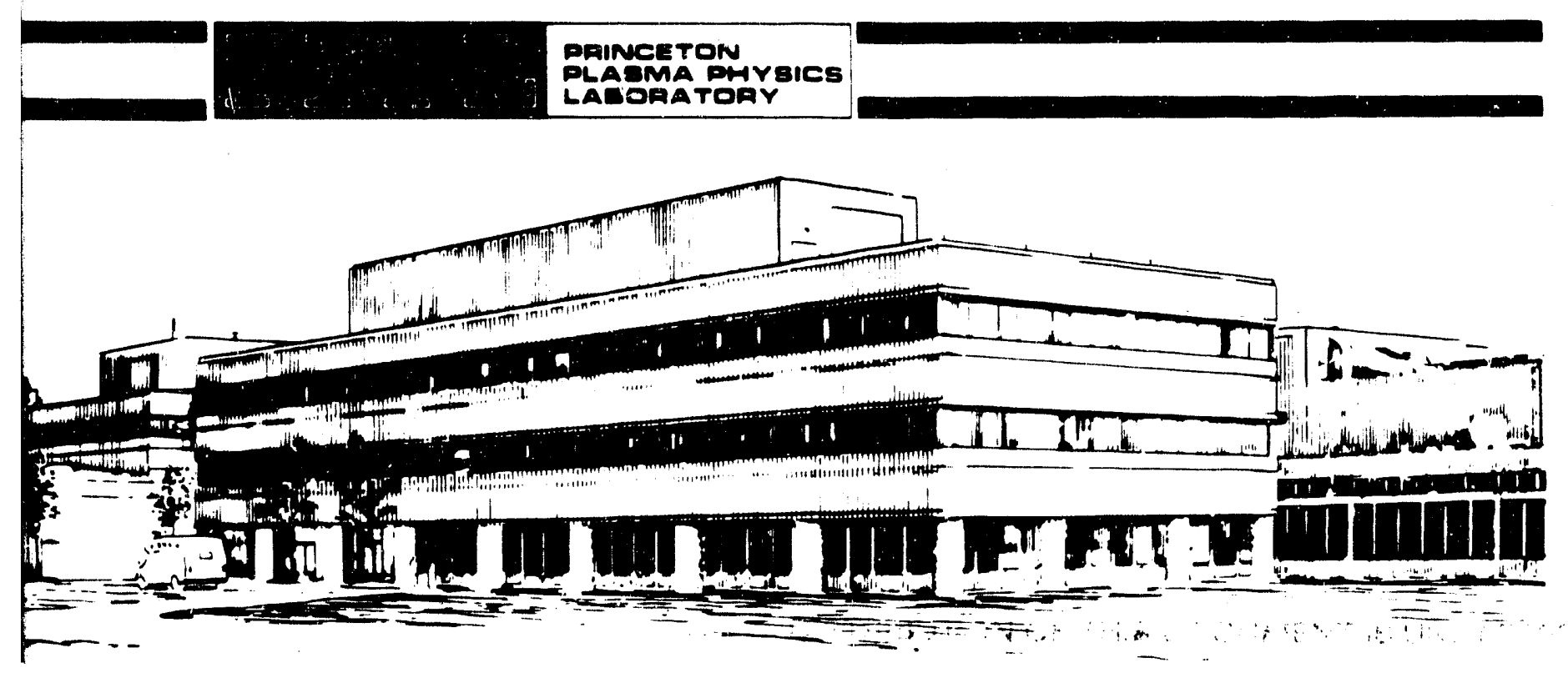




\section{NOTICE}

This report was prepared as an account of work sponsored by an agency of the United States Government. Neither the United States Government nor any agency thereof, nor any of their employees, makes any warranty, express or implied, or assumes any legal liability or responsibility for the accuracy, completeness, or usefulness of any information, apparatus, product, or process disclosed, or represents that its use would not infringe privately owned rights. Reference herein to any specific commercial produce, process, or service by trade name, trademark, manufacturer, or otherwise, does not necessarily constitute or imply its endorsement, recommendation, or favoring by the United States Government or any agency thereof. The views and opinions of authors expressed herein do not necessarily state or reflect those of the United States Government or any agency thereof.

\section{NOTICE}

This report has been reproduced directly from the best available copy.

Available to DOE and DOE contractors from the:

Office of Scientific and Technical Information P.O. Box 62

Oak Ridge, TN 37831 ;

Prices available from (615) $576-8401$.

Available to the public from the:

National Technical Information Service

U.S. Department of Commerce 5285 Port Royal Road

Springfield, Virginia 22161

703-487-4650 
PPPL -2807

DE92 006818

\title{
Spitzer or Neoclassical Resistivity: A
}

\section{Comparison Between Measured and Model}

\section{Poloidal Field Profiles on PBX-M}

\author{
S.M. Kaye, F.M. Levinton; R. Hatcher, R. Kaita, \\ C. Kessel, B. LeBlanc, D.C. McCune and S. Paul \\ Princeton Plasma Physics Laboratory \\ Princeton University \\ Princeton, N.J. 08543
}

\begin{abstract}
Direct measurements of the radial profile of the magnetic field line pitch on PBXM [Phys. Fluids B, 2, 1271 (1990)], coupled with model predictions of these profiles allow a critical comparison with the Spitzer and neoclassical models of plasma parallel resistivity. The measurements of the magnetic field line pitch are made by
\end{abstract}

- Fusion Physics and Technology, Torrance, Cal. 
Motional Stark Effect polarimetry, while the model profiles are determined by solving the poloidal field diffusion equation in the TRANSP transport code using measured plasma profiles and assuming either Spitzer or neoclassical resistivity. The measured field pitch profiles were available for only seven cases, and the model profiles were distinguishable from each other in only three of those cases due to finite resistive diffusion times. The data in two of these three were best matched by the Spitzer model, especially in the inner half of the plasma. Portions of the measured pitch profiles for these two cases and the full profiles for other cases, however, departed significantly from both the Spitzer and neoclassical models, indicating a plasma resistivity profile different from either model. 


\section{Introduction}

Knowledge of the toroidal current profile is one of the key elements in assessing discharge equilibrium, stability, and, arguably, confinement. Because of the sophisticated diagnostic techniques required to measure the current profile, however, it has been one of the least directly measured plasma properties. Consequently, whether the Spitzer resistivity model ${ }^{1}$ alone or with trapping corrections ${ }^{2,3}$ best describes the parallel electrical properties of tokamak plasmas, and under what conditions each applies, is a question that is yet to be answered in a definitive manner.

Most previous determinations of the plasma current profile, or appropriate resistivity model, have been obtained by solving the poloidal magnetic field diffusion equation and comparing model and measured single point or scalar parameters. For instance, comparisons were made between the measured and predicted $Z_{\text {eff }},{ }^{4,5}$ loop voltage ${ }^{\theta-\theta}$ or the location of the $q=1$ surface. ${ }^{10}$ Another technique involved comparing the plasma resistivity as determined from the time evolution of the poloidal flux with Spitzer and neoclassical resistivity profiles determined using local measurements of $T_{e}, n_{e}$, and $\bar{Z}_{e f f .}{ }^{11}$ The results of these comparisons were mixed; some, most notably from small to medium sized devices, favored Spitzer, ${ }^{4,5,7}$ some, from larger and hotter devices favored neoclassical. ${ }^{8-10}$ Another result indicated agreement with neoclassical during the steady-state protion of the discharge, but a resistivity enhanced from neoclassical during the transient current rise phase of the discharge ${ }^{11}$ Early PDX results from neutral beam heated discharges indicated better agreement with neoclassical at higher toroidal field $(2.2 \mathrm{~T})$, but better agreement with Spitzer 
at lower toroidal field $(\leq 1.5 \mathrm{~T}){ }^{6}$

Some direct measurements of the current or q-profile have been attempted. The shift of fast ion orbits within $r=a / 4$ was used to monitor central current diffusion during discharge start-up in $\mathrm{PDX},{ }^{12}$ while Faraday Rotation was used to measure $j(r)$ in TEXTOR. ${ }^{13,14}$ Other recent determinations of sawtooth-averaged current density profiles were obtained on TEXT using $\mathrm{Li}$ beam polarization, ${ }^{15} \mathrm{Li}$ beam fluorescence, ${ }^{16}$ ablation from hydrogen pellets, ${ }^{17}$ and fractional circular polarization of TiXVII. ${ }^{18}$ All but the hydrogen pellet ablation technique gave profiles that were in better agreement with the Spitzer than with the neoclassical model of resistivity. ${ }^{18,19}$

In this report we will compare measured profiles of the magnetic field line pitch ( $\alpha=\tan ^{-1} \frac{B_{p}}{B_{t}}$, where $B_{p}$ and $B_{t}$ are the poloidal and toroidal magnetic fields respectively) with those determined from the two resistivity models. We conclude from this comparison that while the Spitzer model shows the best agreement with data, especially in the innor half of the discharge, there are significant differences between the model and measured profiles. This indicates the possible presence of both particle detrapping (and/or loss) and anomalous current diffusion processes.

\section{PBX-M Device and Analysis Method}

The goal of the PBX-M experiment is to employ current and pressure profile control techniques to enhance the plasma stability and confinement, and to access the second regime of stability to ideal ballooning modes. In addition to the active profile control methods as a means of enhancing plasma stability, PBX-M operates 
with plasmas indented on the in-board major radius side, and with a close-fitting passive stabilizing shell in order to reduce further internal and surface ideal magnetolydrodynamic (MHD) modes. Fig. 1 is a flux surface plot of a PBX-M high$\beta_{p}$ equilibrium with the surrounding conducting shell. The discharge parameters were $\beta_{t}=3.0 \%, \beta_{p}=2.8, \beta_{t} / \frac{I_{p}}{a B_{t}}=3.3, I_{p}=350 \mathrm{kA}, B_{t}=1.34 \mathrm{~T}, P_{\text {inj }}=$ $5.0 M W, a_{\text {mid }}=0.28 \mathrm{~m}, R=1.66 \mathrm{~m}$, elongation $=1.6$, and indentation $=0.15$, where the indentation is defined as $d / 2 a$, with $d$ being the difference in major radial positions of the bean tips and outer flux surface at the mid-plane on the in-board side, and $2 a$ being the difference in major radial positions of the bean tips and the outer flux surface at the mid-plane on the out-board side. A more detailed description of the PBX-M experiment and results can be found in Bell et al ${ }^{20}$ and Sauthoff et al. ${ }^{21}$ Detailed knowledge of the toroidal current profile in PBX-M is necessary in order to compute accurately the plasma equilibrium and stability properties. To this end, a novel technique for measuring the poloidal magnetic field was developed. The technique uses the motional Stark effect (MSE) polarization of the spectral emission from neutral hydrogen particles to determine the magnetic field line pitch (defined above). ${ }^{22,23}$ The MSE diagnostic used for this provided a single-point mid-plane measurement, and building up a profile of between six and ten radial points required a series of twenty-five to forty reproducible $\left(I_{p}=\right.$ constant $\left.\pm 5 \%\right)$ discharges, iimeaveraging for $40 \mathrm{msec}$ in each discharge. A discussion of the calibration of the MSE diagnostic, as well as of the sources and implications of the systematic and random errors can be found in Levinton et al. ${ }^{22}$ 
The measured magnetic field line pitch profiles were used to identify directly which resistivity model best described the PBX-M data by comparing them to field line pitch profiles calculated by the fully time-dependent solution of the poloidal field diffusion equation in the TRANSP code. ${ }^{24}$ A detailed description of this calculation is given in Zarnstorff et. al. ${ }^{10}$; briefly, measured radial profiles of $T_{e}, T_{i}, n_{e}$ and $Z_{\text {eff }}$, along with the beam pressure profile as determined by the beam Monte-Carlo calculation in TRANSP, were used to produce the total pressure profile. Calculations of the beam-driven and bootstrap currents along with the plasma resistivity (based on the Spitzer or neoclassical models) are used to solve simultaneously Ohm's, Ampere's, and Faraday's Laws to determine the poloidal magnetic field at that time. The internal plasma equilibrium is determined by solving the Grad-Shafranov equation using this pressure and $q$ information. The external plasma boundary in this calculation is fixed, having been determined from an extended current distribution code performing a least squares fit to the total plasma current and external flux loop signals. This treatment is similar to that of a filament code..$^{25}$ The plasma rotation is not included in the equilibrium calculation. For cases in which Spitzer resistivity was assumed, the bootstrap current, which depends on the presence of trapped ions, is turned off. As mentioned, the calculation is fully time-dependent, so that the complete time evolution of $B_{p}(r)$ can be determined if data from enough of a discharge time history exists. For most of the cases studied, enough kinetic profile data were available to construct analysis runs to obtain the poloidal field time evolution from ohmic through the period of neutral beam injection. For instance, for the cases to be detailed in this report, between six and nine $T_{e}(R), n_{e}(R)$, and $Z_{e f f}(R)$ profiles from reproducible 
discharges were concatenated to model the time evolution of the particular type of discharge. This procedure gave coverage of one profile every 20 to $60 \mathrm{msec}$. The $T_{e}$ and $n_{e}$ profiles were measured by the 56 -point Thomson scattering diagnostic, and $Z_{\text {eff }}$ was measured by the tangentially-viewing midplane visible bremsstrahlung array. $T_{i}$ data at up to eleven radial positions were obtained every $10 \mathrm{msec}$ throughout the discharge. The total stored energy as determined by TRANSP was typically within $15 \%$ of that as determined by fitting magnetic flux measurements.

In all cases, the MSE data points represent averages over a sawtooth period. As previously discussed, the MSE data were $40 \mathrm{msec}$ averages, and the sawtooth period was typcially 40 to $50 \mathrm{msec}$ for those cases in which sawteeth were present. Since the timing of the sawteeth was not reproducible from shot-to-shot, and since each MSE data point shown is averaged over many discharges, sawtooth effects were averaged out. In addition, the kinetic profiles used as a basis for the TRANSP runs also represent sawtooth-averages, and no sawtooth model was used in the TRANSP calculation. Previous work ${ }^{14}$ have indicated only small $(<10 \%)$ changes in axial current density through the sawtooth period.

The comparison between measurement and model is made using the magnetic field pitch profiles as the variable of interest. This variable has the advantage that it is the "rawest" form of data; comparing q-profiles, for inst nce, involves taking gradients of the measured pitch profiles (for data near the magnetic axis) and knowing the plasma shape in order to transform the local measurement to a flux surface quantity. This additional processing necessarily increases the uncertainty inherent in the comparison. 


\section{Analysis Results}

In order to focus on the differences of the resistivity models as much as possible in this study, the discharges chosen for the analysis were steady-state $\left(\partial I_{p} / \partial t \approx 0\right.$ for $\approx 200 \mathrm{msec}$ ). Typical discharge parameters were $a=0.28 \mathrm{~m}, R=1.65 \mathrm{~m}, I_{\mathrm{p}}=$ $350 \mathrm{kA}, B_{t}=1.35 T$, elongation $=1.8$, indentation $=15 \%, \bar{n}_{e}=6 \times 10^{19} \mathrm{~m}^{-3}, T_{e}(0) \leq$ $2 \mathrm{keV}$, and $T_{i}(0) \leq 4.5 \mathrm{keV}$. The dischargus had 2.5 to $5 \mathrm{MW}$ of $D^{0}$ injection into $D^{+}$plasmas in either the co- or counter-injection directions. In PBX-M, two of the four neutral beams are oriented in the tangential direction $\left(R_{t a n}=1.36 \mathrm{~m}\right)$ and two are oriented in the perpendicular direction $\left(R_{\text {tan }}=0.35 \mathrm{~m}\right)$. The seven cases studied were: ohmic, two-beam co-tangential injection early in the neutral injection phase, two-beam counter-tangential injection (early and late in the neutral injection phase), two-beam counter-perpendicular (early and late), and four-beam co injection (perpendicular + tangential) late in the neutral injection phase.

Fig. 2 is an example of the four-beam co injection case with $5 M W$ of injected power. The onset of injection was at $t=250 \mathrm{msec}$, with the beam on times staggered at $50 \mathrm{msec}$ intervals. In this case the two tangential beams were injected first. As is seen in the divertor $D_{\alpha}$ trace, an $\mathrm{H}$-mode transition occurred at approximately $t=380$ msec. PBX-M H-mode discharges exhibited the usual H-mode features: flat density profiles and confinement times up to $2.5 \tau^{I T E R-89 P}{ }^{26}$ For the discharge shown in the figure, the period of good confinement lasted until about $460 \mathrm{msec}$, at which time a large Edge Localized Mode (ELM) caused a sudden loss of plasma energy. The plasma energy content was reduced further by the presence of large amplitude, low- 
n continuous MHD mode activity and subsequent mode locking. It should be noted that no $\mathrm{H}$-mode transitions were observed in the counter-injection plasmas, even with injection powers up to $5 \mathrm{MW}$. In these counter-injection plasmas, especially those with tangential injection, radiation losses increased steadily during the neutral beam injection phase, reaching levels of $70 \%$ of the input power towards the end of the auxiliary heating phase.

Figure 3 shows the measured temperature (Fig. 3a) and thermal density (Fig. 3b) profiles for the $5 \mathrm{MW}$ co-injection case. Also shown (Fig. 3c) is the plasma pressure profile as determined from the above measured thermal profiles, the beam pressure profile as computed in TRANSP, and the total pressure profile (the sum of the plasma and beam contributions). The profiles are plotted out to the $95 \%$ flux surface. As can be seen, the temperature and density profiles are typical of H-modes; the density is relatively flat and high near the plasma edge, and the edge $T_{e}$ is $\simeq 400 \mathrm{eV}$. The beam pressure accounts for one-half of the total pressure in the center of the discharge, and approximately $30 \%$ of the total volume-integrated energy in the discharge. In this case, $Z_{\text {eff }}$ was relatively flat across the discharge, being 2.4 at the center and rising to 3.0 at the edge.

Of considerable importance in the model calculation, especially for ti: $:$ relatively short-lived PBX-M discharges, is the initial (just before the start of neutral beam injection) value of $q_{0}$, this parameter, in part, constraining the poloidal field profile at this time. Because of finite resistive diffusion times, calculated poloidal field profiles early in the neutral beam phase are heavily dependent upon the initial poloidal field 
profile, regardless of which resistivity model was chosen. This is because at early times the features that distinguish the two resistivity models (i.e., trapped electrons, bootstrap current) have not had sufficient time to modify the poloidal magnetic field. Consequently, at early times in the neutral injection phase, little difference between the model field line pitch profiles based on the two resistivity models was seen. Only later in the calculation, when the poloidal field has had time to respond to these effects, and as the discharge approached magnetic steady-state, could differences in the two model profiles be consistently and clearly discerned. We will concentrate our analysis on these time periods. For the analyses, the initial value of $q_{0}$ was taken to be 0.72 ; this value was obtained from measurements during the counter-injection experimental run. Since the ohmic target plasmas were similar during the co- and counter-injection runs, and since sawteeth were observed during the ohmic phase of the co-injection discharges, we have assumed an initial $q_{0}$ value of 0.72 in the coinjection case as well. The sensitivity of the results to the value of this parameter will be discussed later on. The initial value of $q_{0}=0.72$, along with the kinetic profiles measured at that time and constraints such as $I_{p}$ and $\dot{I}_{p}$, were used to determine an initial equilibrium consistent with Maxwell's equations and the chosen resistivity model. As discussed before, the outer boundary of the plasma was determined from fitting the external magnetic data.

The ratio of the time rate of change of the poloidal field energy (including energy changes due to compression or expansion) to the total ohmic heating is a figure of merit that can be used to determine how close to magnetic steady-state the discharge in the model calculation is. In steary-state, the value of this ratio should be small, and 
the radial profile of the toroidal electric field should be flat. The two cases of interest that we will concentrate on $>$ re the two-beam counter-perpendicular and four-beam co-injection cases. The ratios of the $\partial / \partial t$ terms to the total ohmic heating terms for these two cases were determined with each numerator and each denominator volume integrated to $r=a / 2$ (within the region of MSE data). In both cases, the discharges were near magnetic steady-state, at the times the MSE data were taken, with the ratio of $\partial / \partial t$ terms to the total ohmic heating terms being $10 \%$ for the two-beam counter-perpendicular case and $20 \%$ for the four-beam co-injection case.

An example of the comparison between the measured and model magnetic field line pitch profiles is shown in Fig. 4. 'This example is taken from the late phase of the two-beam counter-perpendicular injection discharge (approximately $230 \mathrm{msec}$ into the neutral beam injection phase). Major discharge parameters for this and for the four-beam co-injection case (Fig. 5) are given in Table I. For the two-beam counter-injection case, $Z_{\text {eff }}$ rose from 2.0 at the center to 4.0 at the edge. Plotted in Fig. 4 are the MSE measurements (asterisks) with error bars, and the model field line pitch profiles assuming the Spitzer model with no bootstrap current (solid lines) and the neoclassical model with bootstrap current (dashed lines) as functions of major radius. The absolute value of the field line pitch is plotted; actually, $B_{p}$, and thus $\alpha$, reverse sign across the current center. Note that the uncertainties in the MSE measurement are about twice as large nearer the edge than at the center. For this, and subsequent analysis, the measured and the model profiles were shifted with respect to each other in order to bring the current centers ( $R_{\alpha=0}$ of the MSE measurement and the model into agreement. The shift required for this was, for most 
cases, $<1 \mathrm{~cm}$, which is well within the approximately $2 \mathrm{~cm}$ position uncertainty of the MSE measurement. The uncertainty in the position of the magnetic axis as computed from the magnetics is small compared to the position uncertainty of the MSE measurement. This uncertainty is deduced by comparing results from the magnetics calculation with those from a more detailed equilibrium calculation that incorporates the measured thermal pressure profile, the MSE data, and the computed beam pressure profile. The difference in positions of both the magnetic axis and geometric center (center of the outer flux surface on the midplane) was found to be 3 to $4 \mathrm{~mm}$.

As can be seen in Fig. 4, the measured pitch values on average are considerably lower than those of the neoclassical model, and, in fact, are in reasonably good agreement with the Spitzer model at all radii. The standard deviation of the measured points from the Spitzer and neoclassical values are $0.44^{\circ}$ and $0.88^{\circ}$ respectively. For comparison, the uncertainty of the MSE measurement in the inner region of the plasma is $\leq 0.5^{\circ}$, indicating that the difference between model and measurement is more than just measurement uncertainty. Also, the difference between the Spitzer and neoclassical models themselves is approximately $0.7^{\circ}$ at $R=173 \mathrm{~cm}$, indicating that the models are distinguishable relative to both the measurement uncertainty and the mode-measurement standard deviation.

The second comparison is from the late phase of the four-beam co-injection discharge whose summary plot was shown in Fig. 2. As a reminder, the beams in this discharge were turned on sequentially at $50 \mathrm{msec}$ intervals starting at $t=250 \mathrm{msec}$. 
The H-mode transition occurred at $t=380 \mathrm{msec}$, and the comparison, shown in Fig. 5, was made at $t=450 \mathrm{msec}, 50 \mathrm{msec}$ after the last beam was activated. Quantitatively, the standard deviations of the data from the models are 0.35 and $0.69^{\circ}$ for Spitzer and neoclassical respectively. The difference between the two models is $\approx 0.6^{\circ}$ at $R=173 \mathrm{~cm}$. These issues notwithstanding, the overall agreement with Spitzer is better than with neoclassical, with good agreement seen in the inner region of the discharge $(160 \leq R \leq 175 \mathrm{~cm})$.

Although by far the largest uncertainty affecting the field pitch profiles computed in TRANSP is the choice of the resistivity model, both the beam and thermal profiles used in the calculation have uncertainties associated with them. As will be discussed later on, there is evidence in the $5 M W$ co-injection case that some fast ions were being loss in the presence of an $n=1$ magnetohydrodynamic (MHD) mode. However, the field pitch profile calculated from a TRANSP run with this fast ion loss included does not differ from that when no fast ion loss is included in the calculation. This is because the fast ion loss represents only a $20 \%$ decrease in the fast ion energy, and, since the fast ions are only $30 \%$ of the total stored energy without loss, only only a $\approx 6 \%$ decrease in total stored energy.

The kinetic $\left(T_{e}, T_{i}, n_{e}\right)$ profiles also have inherent uncertainties that inight affect the values of the computed poloidal field profiles. In order to determine the magnitude of this effect, a series of TRANSP runs were made in which the $T_{e}$ and $n_{e}$ profiles were systematically varied. The results indicated only a small change in the computed $B_{\text {pol }}(r)$. Increasing $n_{e}$ by $15 \%$ caused a reduction of $B_{\text {pol }}$ by only $5 \%$ at $r=10 \mathrm{~cm}$ 
$(R \simeq 1.77 \mathrm{~m})$. A change in $T_{e}$ by $10 \%$ resulted in a change in the computed $B_{p o l}$ of $8 \%$ (also at $r=10 \mathrm{~cm}$ ).

As mentioned earlier, the final calculated field line pitch profile can be dependent on the initial value of $q_{0}$. Fig. 6 shows the results of a test of the sensitivity of the results for the four beam co-injection case to the choice of this parameter. TRANSP runs were made for four values of the initial $q_{0} ; 0.45,0.72,0.9$, and 1.2 . The field line pitch profiles for the Spitzer model assumption are shown along with the MSE data in the figure. As is seen, higher initial $q_{0}$ values lead ultimately to lower pitch values, and for this case, better agreement with the MSE measurements. However, as the ohmic portion of the plasma was sawtoothing, we take the case with initial $q_{0}=1.2$ (or any $q_{0} \geq 1$ ) to be unrealistic. For the total range of $q_{0}=0.45$ to 1.2 , the range of calculated pitch values is $\approx 1.25^{\circ}$ at $R=173 \mathrm{~cm}$ However, without considering the initial $q_{0}=1.2$ case, the range of $\alpha$ is much smallcr, and, in particular, is smaller $\left(0.6^{\circ}\right.$ at $\left.R=173 \mathrm{~cm}\right)$ than the difference between the Spitzer and neoclassical is odels in this part of the discharge.

Figure 7 shows the comparison betwetn measurement and model calculations for the two-beam tangential counter-injection case late in the neutral beam injection phase. As can be seen, th: measured data do not agree well with either of the two models. In particular, near the center of the discharge, the gradient of the field line pitch, which is proportional to $q$, is much less than those in either model. In fact, comparing $q_{0}$ values directly for this case at this time, the MSE data yield $q_{0}=1.2$, while $q_{0}=0.8$ and 0.65 for the Spitzer and neoclassical models respectively. On the 
other hand, at larger radius, the measured data indicate lower local $q$-values than were calculated. For this case, therefore, the measurements suggest a broader current profile than does either of the two models. The two-beam tangential co-injection case (not shown) is another e; ample in which the measured field line pitch profiles do not agree well with either model, also with the measured current profile broader (with lower central current density) than those calculated from the two models.

\section{Summary and Discussion}

One objective of this report was to show how the results of the relatively new method of measuring the internal magnetic field pitch directly can be used to address the issue of how best to model the plasma electrical resistivity. This was done by comparing the MSE measurements of magnetic field line pitch with model profiles determined from a time-dependent solution of the poloidal magnetic field diffusion equation using measu'ed kinetic profiles as input and assuming either Spitzer or neoclassical resistivity. The results of this comparison should be treated with caution, as only a few cases were studied, and in these cases the difference between the Spitzer and neoclassical models was not optimized. Nevertheless, the results of the comparison do indicate that neither the Spitzer or neoclassical models reproduce the measured field line pitch profiles exactly. Of the two moitels, the Spitzer model does provide the best agreement with the data (where the two models can be distinguished and where there is some agreement between the data and the model values). As noted in the previous section, the agreement between the data and the Spitzer model values 
can actually be quite good in the inner $1 / 3$ to $1 / 2$ of the plasma.

That the Spitzer model best reproduces the MSE data indicate one or a combination of several mechanisms at work. Since the difference between the two resistivity models has to do with trapped particle effects, including the existence of the bootstrap current for the neoclassical model, there is either some mechanism modifying the velocity space distribution function of the thermal electrons (e.g., detrapping or loss of the trapped electrons) and/or the quantitative estimate of the bootstrap current is incorrect. The latter effect can be caused, of course, by the former. As the expression for computing the bootstrap current in the TRANSP code $^{3}$ has been checked numerous times for accuracy, we do not believe that this is an issue. Additionally, the local bootstrap current term for either of the two cases shown in Figs. 4 and 5 is $\leq 10 \%$ of the total local current density, indicating that bootstrap effects, as calculated in the code, are not significant. We should also point out that although the TRANSP code properly treats most aspects of a rion-circular plasma, for the purposes of calculating neoclassical corrections the code assumes the plasma flux surface to be a circle with the same cross-sectional area as the actual shaped flux surface. However, a proper treatment of neoclassical effects in shaped plasmas, as outlined by Chang and Kaye, ${ }^{27}$ shows virtually no difference in the result for the plasmas of interest.

Modifying the velocity space distribution function may be accomplished by several mechanisms. It has been well established that energetic ion loss (both parallel and perpendicular ions) is associated with MHD oscillations. During the time periods of interest for the discharges shown in Figs. 4 and 5 , large amplitude, mixed mode 
(low- $n$ ), weak turbulence did exist. For the two-beam tangential counter injection case, the dominant mode was a $9 \mathrm{kHz}, m=2 / n=1$ mode with an amplitude of $\sim 5$ Gauss $\left(\dot{B}_{\theta} / B_{\theta} \sim 0.5 \%\right.$ at a location $12 \mathrm{~cm}$ from the plasma surface near the outer midplane), while for the four beam co-injection case the dominant mode was a $16 \mathrm{kHz}, m=3 / n=1$ mode with an amplitude of $\sim 5$ Gauss $\left(\bar{B}_{\theta} / B_{\theta} \sim 0.3 \%\right.$ at the same location). Fig. 8 shows slowing down spectra from the four beam discharge before $(A)$ and after $(B)$ the onset of this weak turbulence. The spectra were measured along a near-perpendicular sightline of a charge-exchange analyzer; consequently, they reflect the distribution of trapped ions. Furthermore, the detection energy was swept with time, so the data show the temporal behavior as well as the energy dependence of the ions. Oscillations in the ion distribution at high energy are more conspicuous during the weak turbulence phase, and there also appears to be a depletion of ions between 4 and $16 \mathrm{keV}$ (the dashed line in Fig. 8b, plotted for comparison purposes, is the lower energy portion of the slowing down spectrum from before the onset of the weak turbulence, taken from A). Since similar depletions were not observed in spectra from tangentially viewing analyzer sightlines, this suggests that it is the trapped ions that are preferentially lost in the presence of the weak turbulerce, as was the case with fishbones. ${ }^{28}$ The relation between the loss of fast ions and the detrapping or loss of trapped thermal electrons in the presence of this mode is not clear. While the poloidal gyroradius of a perpendicular energetic ion is $\approx 5$ to $10 \mathrm{~cm}$, with a banana width is a good fraction of the plasma minor radius, those of a trapped thermal electron are $\leq 1 \mathrm{~cm}$, indicating that the scale size of the electron motion is most likely much smaller than that of the MHD. In addition, the precession velocity of the 
trapped electrons is smaller (by a factor of 30 ) and in the opposite direction of that of the ion, ruling out a possible wave-particle resonance that is most likely responsible for the loss of the ions. Therefore, it is difficult to see how the large-sale MHD could be responsible for the thermal electron detrapping.

A possible source of detrapping may be electrostatic turbulence that generally occurs in the plasma. Unfortunately, no measurements to detect this type of turbulence in PBX-M plasmas were available at this time, so we can say nothing definitive about this as a possible detrapping mechanism. It is worth pointing out, though, that turbulence scale lengths of order $2 \pi c / \omega_{\text {pe }}$ are approximately the same scale as the widths of the trapped thermal electron banana orbit.

Recent work by Chang ${ }^{29}$ showed that the applied Ohmic electric field can affect significantly the motion of thermal electrons near the trapped-passing boundary. The E-field can actually cause a reversing of the electron parallel motion from the co- to counter-E direction, and thus increase the ohmic current. This has the effect of increasing the value of the neoclassical conductivity by 25 to $30 \%$ for $Z_{i}=1$ plasmas. The ratio of neoclassical to Spitzer conductivity values for $r / a \sim 1 / 3$ to $1 / 2$ in $\mathrm{PBX}$ $M$ ranges from 0.48 to 0.66 ; consequently, $a \approx 30 \%$ increase in these neoclassical conductivity values would bring that model closer, but not quite all the way, to the Spitzer model.

While the results of this work are clearly not a final answer, they indicate that for some situations the use of either Spitzer or neoclassical resistivity to model the plasma resistivity across the entire profile is not justified, and, therefore, understanding cur- 
rent diffusion in plasmas may be as difficult as understanding energy transport. It may actually be that understanding energy transport is contingent on understanding the current transport. This work is a first step towards using newly diagnosed plasma characteristics in addressing this topic. Additional studies are needed; in particular, it is necessary to establish the baseline conditions that amplify the difference between the Spitzer and neoclassical models. In addition, what is needed is to determine the resistivity model appropriate to quiescent (MHD and electrostatic turbulence) plasmas. Furthermore, a more sensible use of the MSE data for this type of analysis is to use the data as input to the solution of the poloidal field diffusion equation to compute the "actual" resistivity profile, and not vice-versa. Improvements in the MSE diagnostic itself, which will lead to reduced error bars and routinely more data to analyze, are presently being made. These improvements will allow full field line pitch profiles to be obtained in a single plasma discharge and with a shorter integration time. 


\section{Acknowledgment}

The authors gratefully acknowledge discussions with W. Park, W. Tang, and M.

Zarnstorff. A portion of this work was supported by the U. S. Dept. of Energy Contract No. DE-AC02-76-CHO-3073. 


\section{References}

${ }^{1}$ L. Spitzer and R. Harm, Phys. Rev. 89, 977 (1953).

${ }^{2}$ F. Hinton and R. Haze: ine, Rev. Mod. Phys. 42, 239 (1976).

${ }^{3}$ S. Hirshman and D. Sigmar, Nucl. Fusion 21, 1079 (1981).

${ }^{4}$ E. Meservey, M. Bitter, C. Daughney, D. Eames, P. Efthimion, E. Hinnov, R. Hulse, D. Post, K. Sato, S. Suckewer, and S. von Goeler, Nucl. Fusion 24, 3 (1984).

${ }^{5}$ H. Rohr, K. Steuer, and the ASDEX Team, Rev. Sci. Inst. 59, 1875 (1988).

${ }^{6}$ S. Kaye, R. Coldston, M. Bell, K. Bol, M. Bitter, R. Forck, B. Grek, R. Hawryluk, D. Johnson, R. Kaita, H. Kugel, D. Mansfield, D. McCune, K. McGuire, D. Mueller, M. Okabayashi, D. Owens, G. Schmidt, and P. Thomas, Nucl. Fusion 24, 1303 (1984).

${ }^{7} J$. Porter, P. Phillips, S. McCool, S. Kim, D. Rowss, W. Miner, and J. Wiley, Nucl. Fusion 27, 205 (1987).

${ }^{8}$ M. Zarnstorff, M. Bell, M. Bitter, R. Goldston, B. Grek, R. Hawryluk, K. Hill, D. Johnson, D. McCune, H. Park, A. Ramsey, G. Taylor, and R. Wieland, Phys. Rev. Lett. 60, 1306 (1988).

${ }^{9}$ M. Kikuchi, M. Azumi, S. Tsuji, K. Tani, and H. Kubo, Nucl. Fusion 30, 2 (1990).

${ }^{10}$ M. Zarnstorff, K. McGuire, M. Bell, B. Grek, D. Johnson, D. McCune, H. Park, A. Ramsey, and G. Taylor, Phys. Fluids B 2, 1852 (1990). 
${ }^{11}$ D. Campbell, E. Lazzaro, M. Nave, J. Christiansen, J. Cordey, F. Schuller, and P. Thomas, Nucl. Fusion 28, 981 (1988).

${ }^{12}$ D. Meyerhofer, R. Goldston, R. Kaita, A. Cavallo, B. Grek, D. Johnson, D. McCune, K. McGuire, and R. White, Nucl. Fusion 25, 321 (1985).

${ }^{13}$ H. Soltwisch, W. Stodiek, J. Manickam, and J. Schluter, in Plasma Physics and Controlled Fusion Research, volume 1, p. 263, Vienna, Austria, 1987, IAEA, Proc. 11th Int. Conf. Kyoto, 1986.

${ }^{14}$ H. Soltwisch, Rev. Sci. Inst. 59, 1599 (1988).

${ }^{15}$ W. West, D. Thomas, J. DeGrassie, and S. Zheng, Phys. Rev. Lett. 58, 2758 (1987).

${ }^{16}$ D. Wroblewski and H. Moos, Rev. Sci. Inst. 57, 2029 (19868).

${ }^{17}$ R. Durst, P. Phillips, and W. Rowan, Rev. Sci. Inst. 59, 1623 (1988).

${ }^{18}$ D. Wroblewski, L. Huang, H. Moos, and P. Phillips, Phys. Rev. Lett. 61, 1724 (1988).

${ }^{19}$ A. Wootton, M. Austin, R. Bengston, J. Boedo, R. Bravenec, D. Brower, J. Chen, G. Cima, K. Conner, T. Crowley, P. Diamond, R. Durst, P. Edmunds, S. Fan, J. Forster, M. Foster, R. Gandy, K. Gentle, G. Hallock, R. Hickok, L. Huang, W. Jennings, J. Kim, S. Kim, H. Lin, N. L. Jr., S. McCool, W. Miner, A. Ouroua, D. Patterson, W. Peebles, P. Phillips, T. Rhodes, B. Richards, C. Ritz, D. Ross, W. Rowan, P. Schoch, D. Sing, E. Synakowski, P. Terry, D. Thomas, D. Wroblewski, X. Yang, X. Yu, and Z. Zhang, in Plasma Physics and Controlled Fusion 
Research, volume 1, p. 293, Vienna, Austria, 1989, IAEA, Proc. 12th Int. Conf. Nice, 1988.

${ }^{20}$ R. Bell, N. Asakura, S. Bernebei, M. Chance, P.-A. Duperrex, R. Fonck, G. Gammell, G. Greene, R. Hatcher, A. Holland, S. Jardin, T.-W. Jiang, R. Kaita, S. Kaye, C. Kessel, H. Kugel, B. LeBlanc, F. Levinton, M. Okabayashi, M. Ono, S. Paul, E. Powell, Y. Qin, D. Roberts, N. Sauthoff, S. Sesnic, and H. Takahahshi, Phys. Fluids B 2, 1271 (1990).

${ }^{21}$ N. Sauthoff, N. Asakura, R. Bell, M. Chance, P. Duperrex, J. Faunce, H. Fishman, R. Fonck, G. Gammel, G. Greene, R. Hatcher, P. Heitzenroeder, A. Holland, S. Jardin, T. Jiang, R. Kaita, S. Kaye, C. Kessel, T. Kozub, H. Kugel, D. Kungl, B. LeBlanc, F. Levinton, J. Manickam, M. Okabayashi, M. Ono, S. Paul, E. Powell, Y. Qin, D. Roberts, S. Schweitzer, S. Sesnic, and H. Takahashi, in Plasma Physics and Controlled Fusion Research, volume 1, p. 709, Vienna, Austria, 1991, IAEA, Proc. 13th Int. Conf. Washington, D.C., 1990.

${ }^{22}$ F. Levinton, R. Fonck, G. Gammel, R. Kaita, H. Kugel, E. Powell, and D. Roberts, Phys. Rev. Lett. 63, 2060 (1989).

${ }^{23}$ F. Levinton, G. Gemm:l, R. Kaita, H. Kugel, and D. Roberts, Rev. Sci. Inst. 61, $2914(1990)$.

${ }^{24}$ R. Hawryluk, in Physics of Plasmas Close to Thermonuclear Conditions, edited by B. Coppi, volume 1, p. 19, Brussels, 1980, CEC.

${ }^{25}$ D. Swain and G. Neilson, Nucl. Fusion 22, 1015 (1982). 
${ }^{26} \mathrm{P}$. Yushmanov, T. Takizuka, K. Riedel, O. Kardaun, J. Cordey, S. Kaye, and D. Post, Nucl. Fusion 30, 1999 (1989).

${ }^{27}$ C. Chang and S. Kaye, Phys. Fluids B 3, 395 (1991).

${ }^{28}$ K. McGuire, R. Goldston, M. Bell, M. Bitter, K. Bol, K. Brau, D. Buchenauer, T. Crowley, S. Davis, F. Dylla, H. Eubank, H. Fishman, R. Fonck, B. Grek, R. Grimm, R. Hawryluk, H. Hsuan, R. Hulse, R. Izzo, R. Kaita, S. Kaye, H. Kugel, D. Johnson, J. Manickam, D. Manos, D. Mansfield, E. Mazzucato, R. McCann, D. McCune, D. Monticello, R. Motley. D. Mueller, K. Oasa, M. Okabayashi, K. Owens, W. Park, M. Reusch, N. Sauthoff, G. Schmidt, S. Sesnic, J. Strachan, C. Surko, R. Slusher, H. Takahashi, F. Tenney, P. Thomas, H. Towner, J. Valley, and R. White, Phys. Rev. Lett. 50, 891 (1983).

${ }^{29} \mathrm{C}$. Chang, private communication, 1991. 


\section{Figures}

FIG. 1. Flux plot of a high- $\beta_{p}$ PBX-M equilibrium in the poloidal plane. Seen also are the various shaping field coils and the close-fitting passive stabilizer plates

FIG. 2. Time history of a four beam co-injection high- $\beta_{p}$ PBX-M H-mode discharge. The MSE measurements were taken at $450 \mathrm{msec}$.

FIG. 3. Temperature, density, and pressure profiles frcm the four-beam co-injection case. The beam pressure shown in Fig. $3 \mathrm{c}$ is computed in TRANSP. The ion thermal density shown in Fig. $3 \mathrm{~b}$ is calculated from the measured $Z_{\text {eff }}$ profile assuming $O^{8}$ to be the only impurity present. The other profiles are measured directly.

FIG. 4. Comparison of MSE field line pitch measurements (asterisks) to field pitch profiles calculated from TRANSP assuming Spitzer (solid line) and neoclassical (dashed line) resistivity for the two-beam perpendicular counter-injection case late in the neutral injection phase. The radial shift of the MSE data relative to the TRANSP results was $0.7 \mathrm{~cm}$.

FIG. 5. Same as Fig. 4 for the four-beam co-injection case. The radial shift of the MSE data relative to the TRANSP results $w a s, 0.3 \mathrm{~cm}$.

FIG. 6. Comparison of measured field pitch values to field pitcit profiles calculated assuming Spitzer resistivity and various initial values of $q_{0}$ for the four-beam coinjection case. 
FIG. 7. Same as Fig. 4 for the two-beam tangential counter-injection case late in the neutral beam injection phase. The radial shift of the MSE data relative to the TRANSP results was $0.5 \mathrm{~cm}$.

FIG. 8. Charge exchange efflux spectra obtained before the onset (a) and after the onset (b) of the weak turbulence in the four-beam co-injection discharge. The spectra were measured along a near-perpendicular sightline. The dashed line in (b) is the lower energy portion of the slowing down spectrum from before the onset of the weak turbulence (taken from a), and is plotted for comparison purposes. 


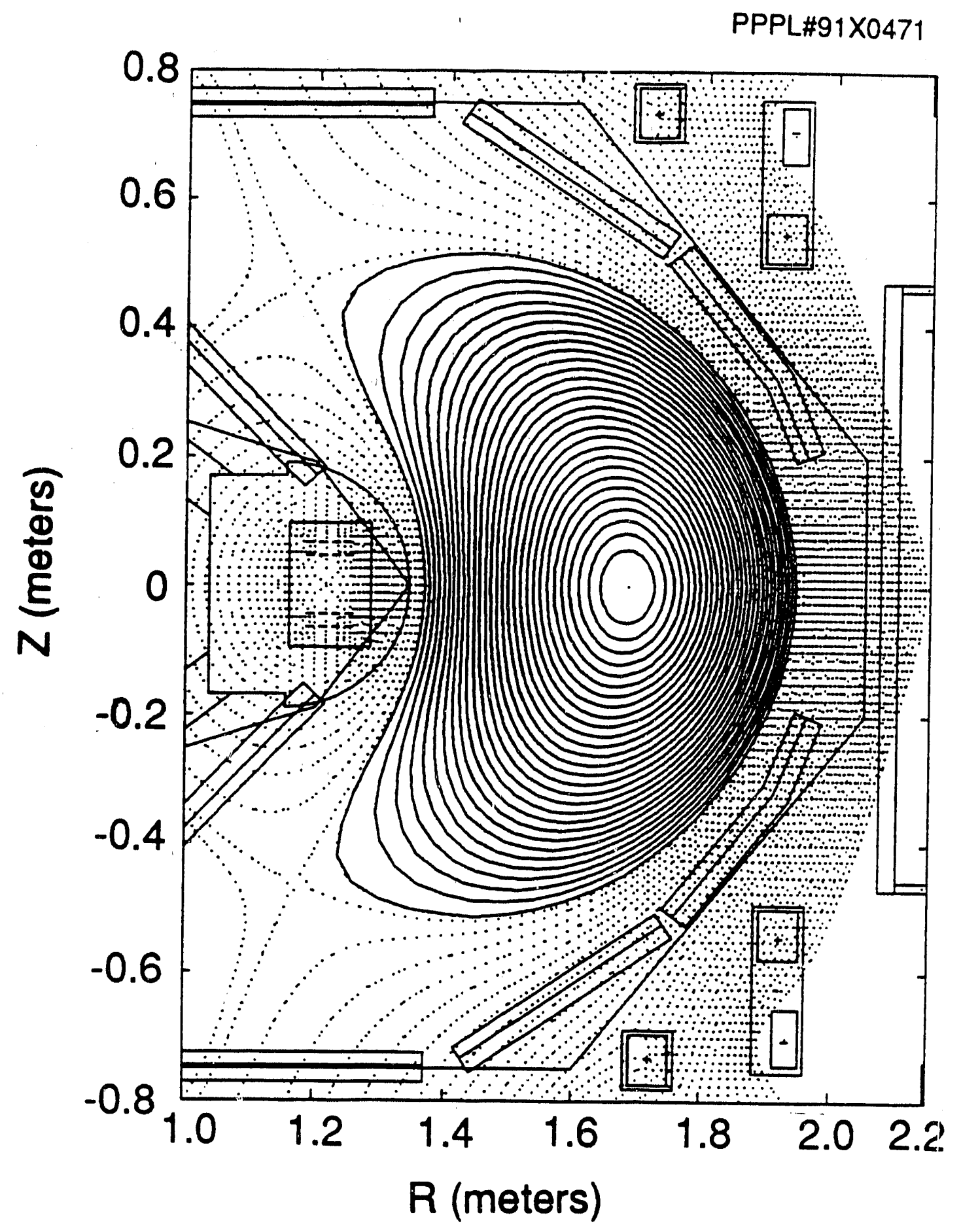

Figure 1 

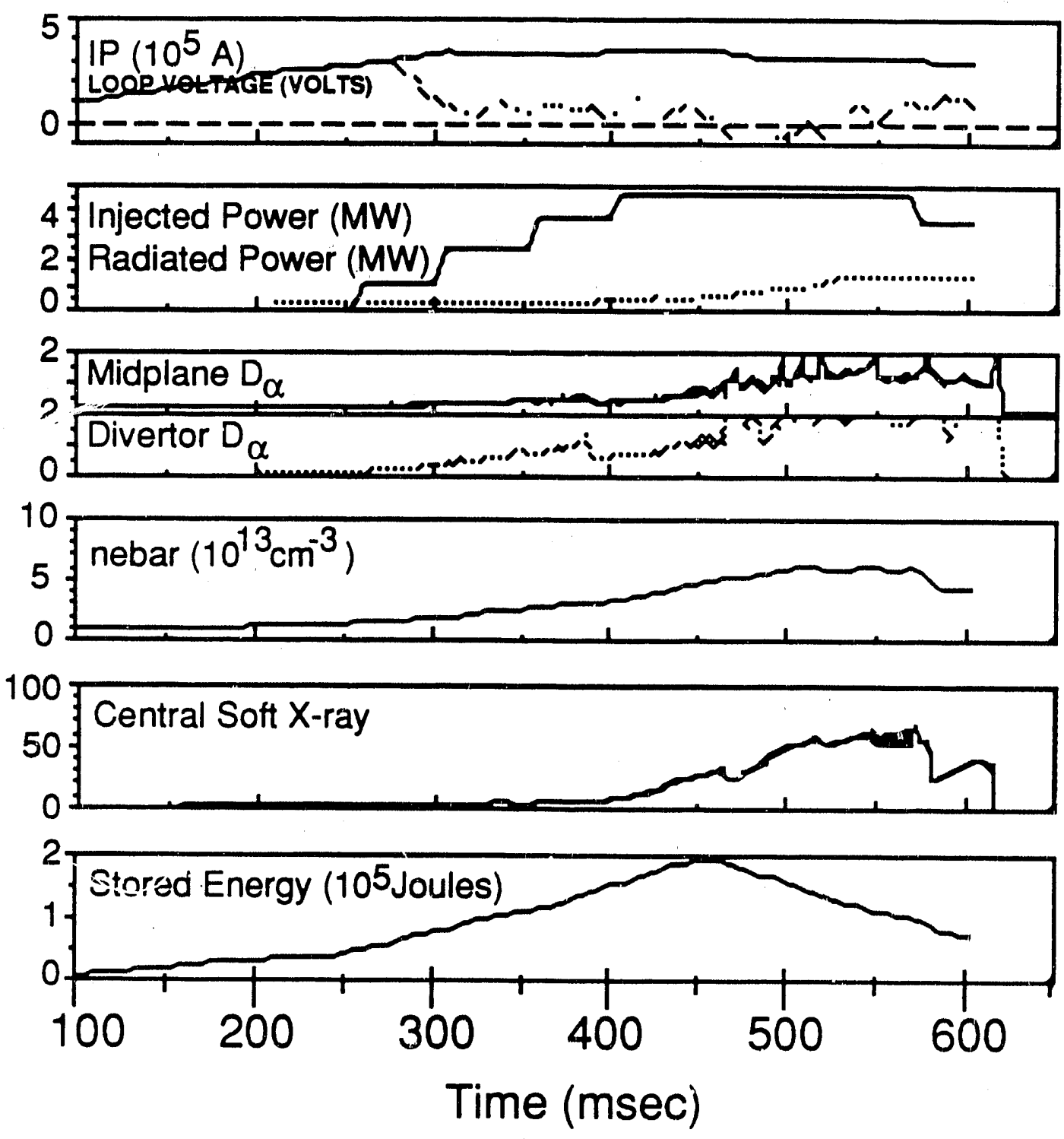

Figure 2 

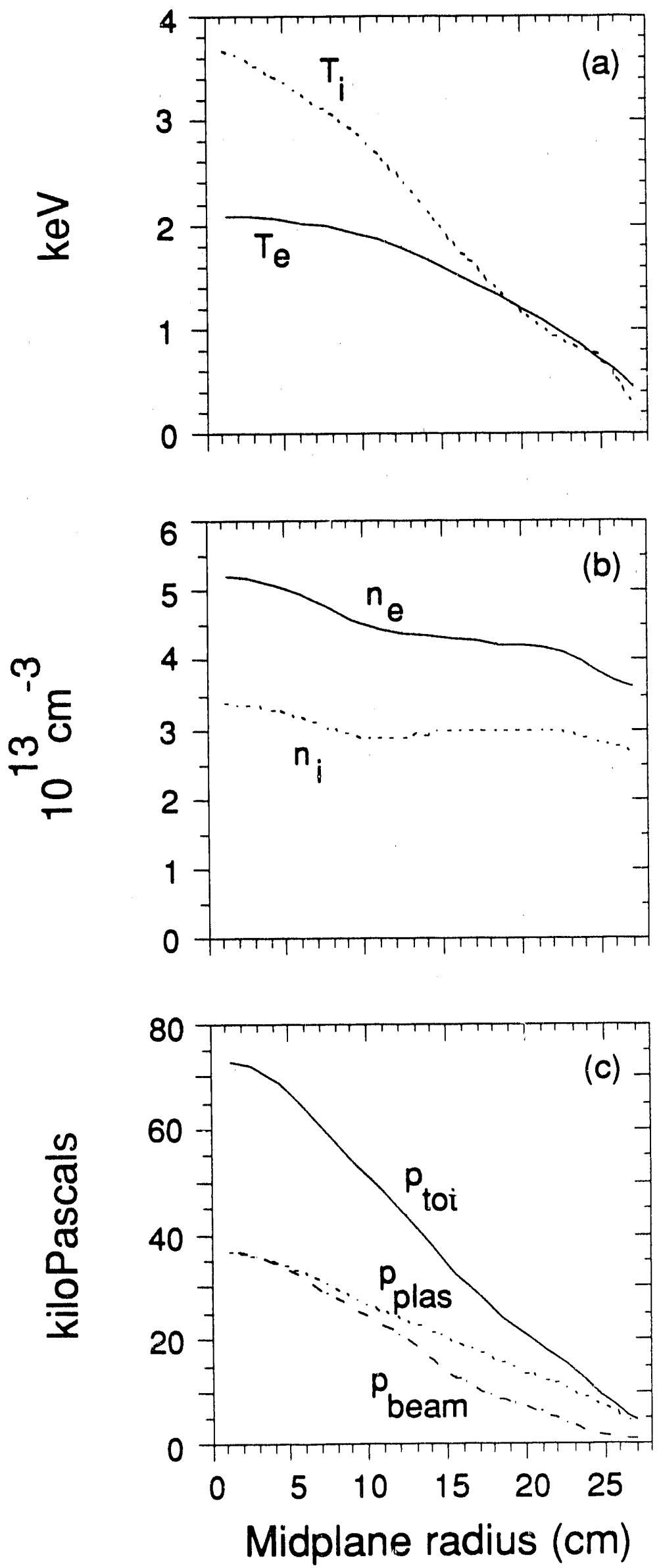

Figure 3 


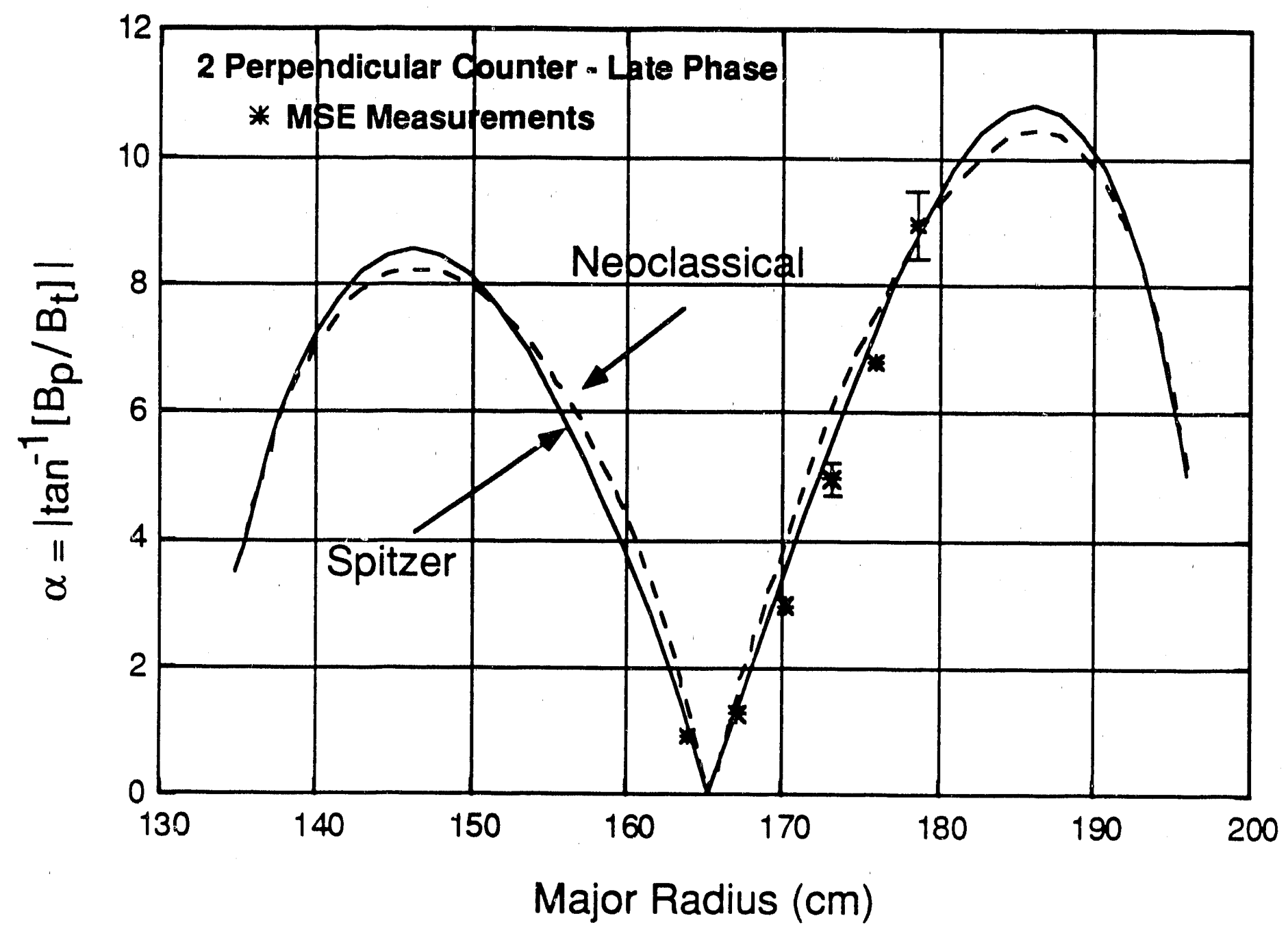

Figure 4 


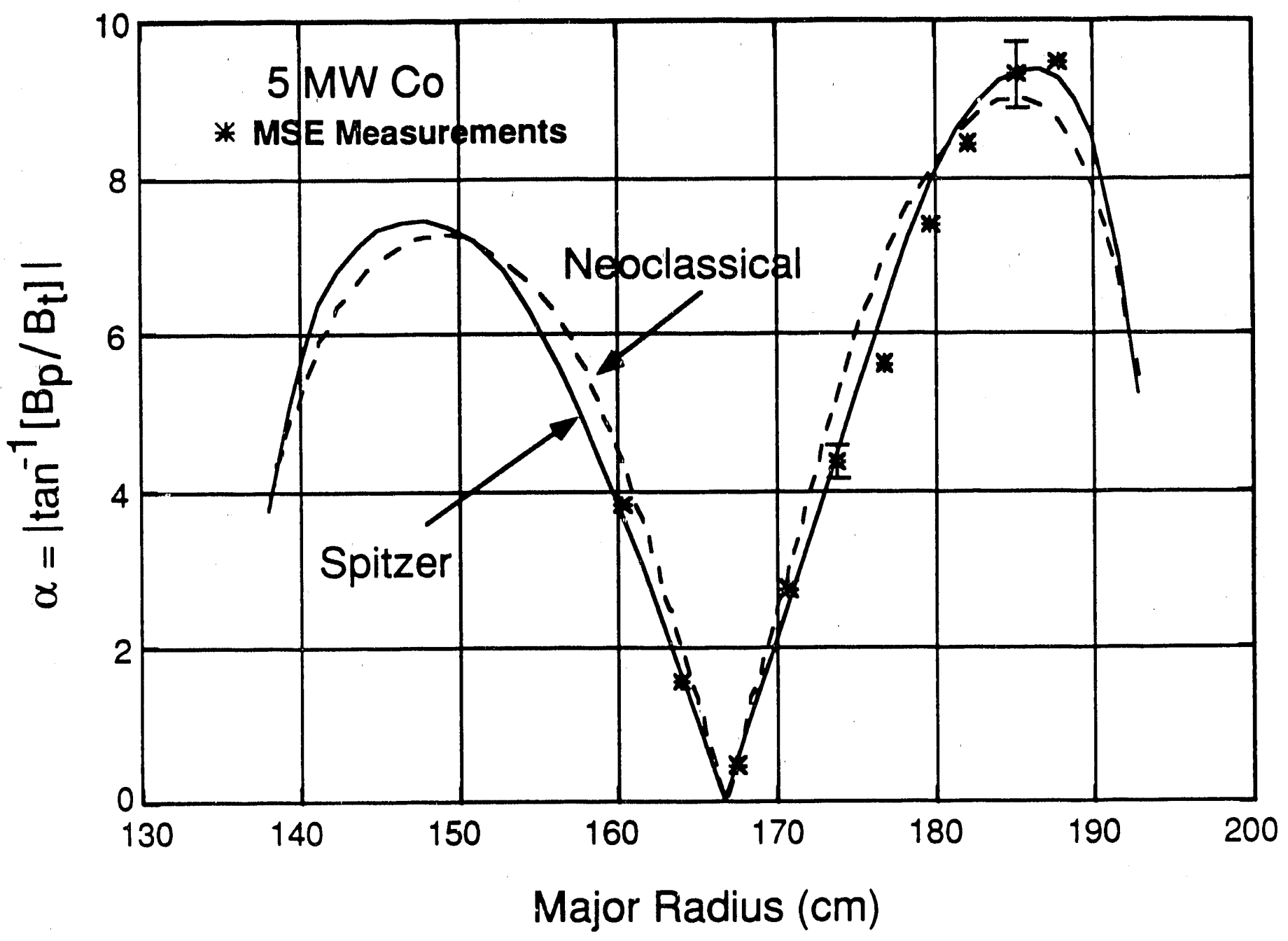

Figure 5 


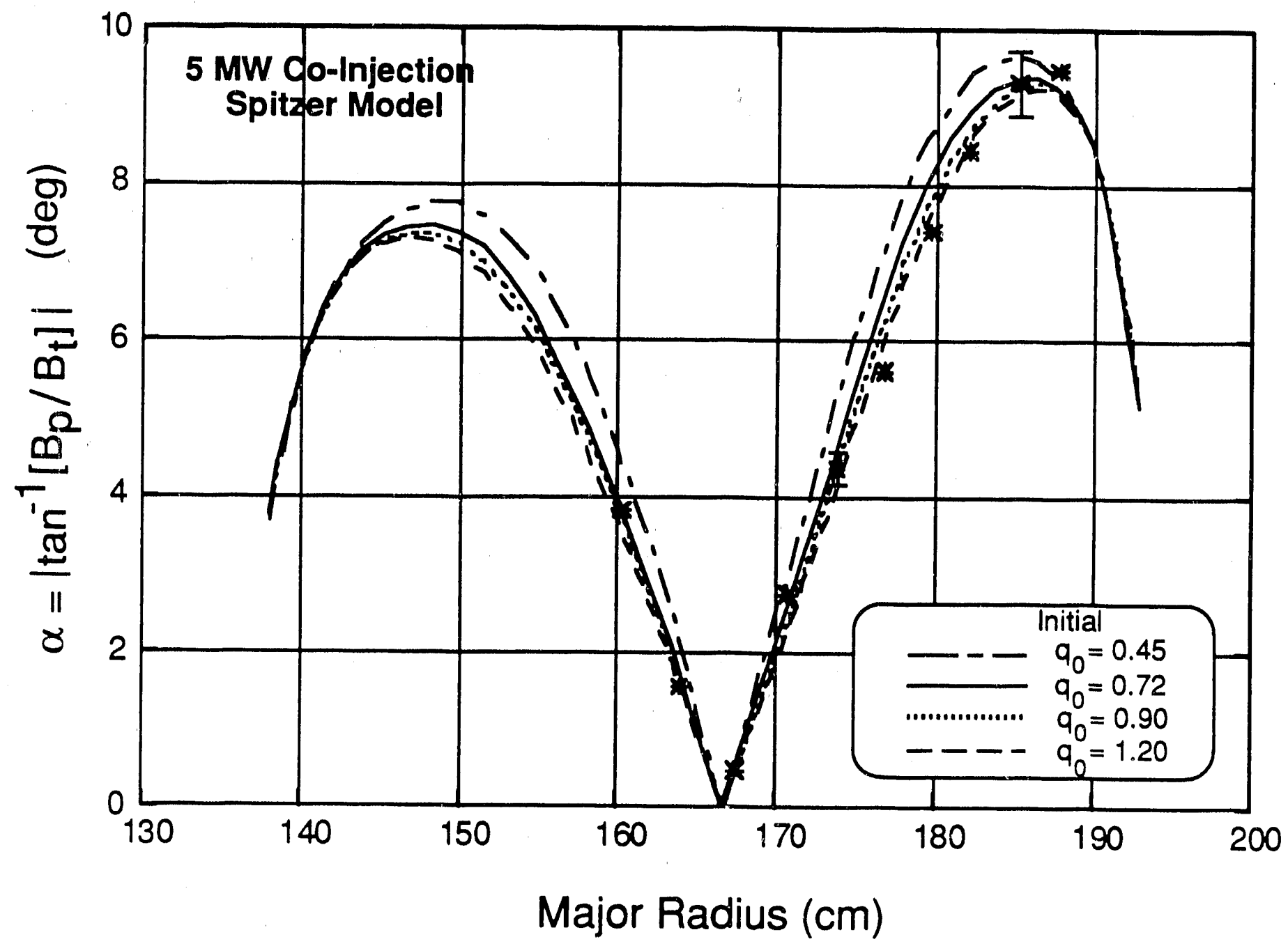

Figure 6 


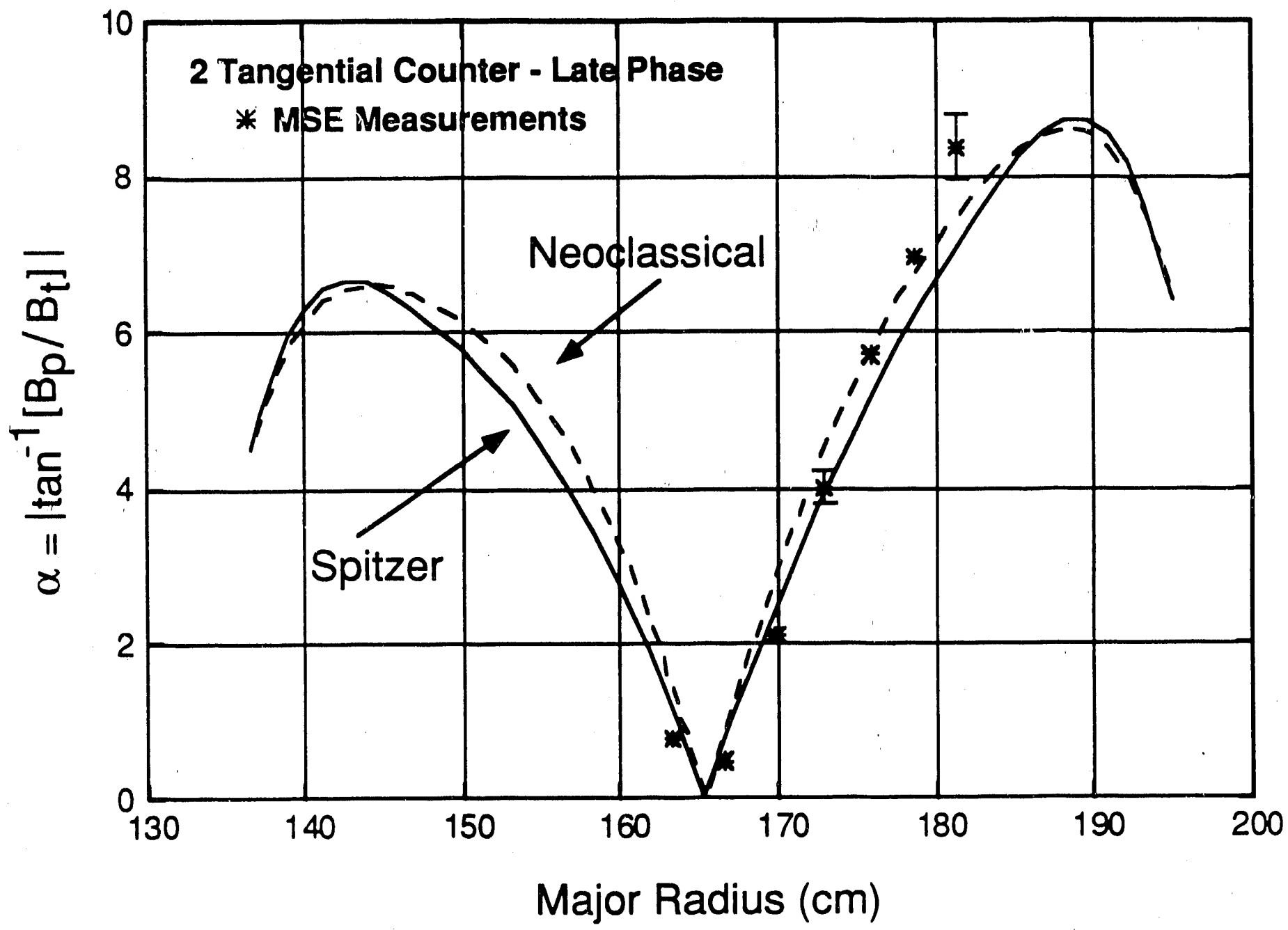

Figure 7 

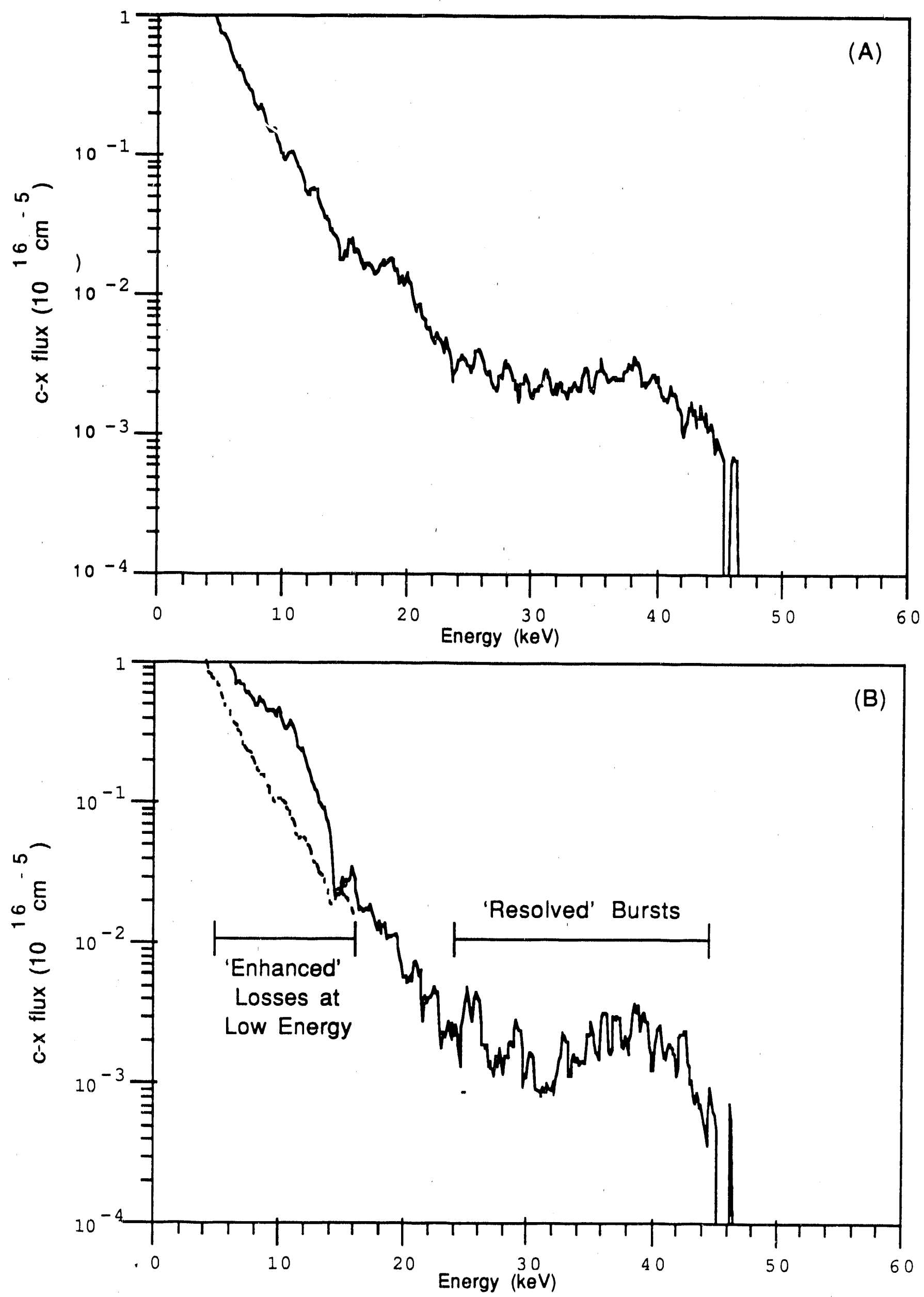

Figure 8 
Dr. F. Paoloni, Univ. of Woliongong, AUSTRALIA

Prof. M.H. Brennan, Univ, of Sydney, AUSTRALIA

Plasma Research Lab., Australian Nat. Univ., AUSTFLALIA

Prof. I.R. Jones, Flinders Univ, AUSTRALIA

Prof. F. Cap, Inst. for Theoretical Physics, AUSTRIA

Prof. M. Heindler, Institut for Theoretische Physik, AUSTRIA

Prof. M. Gooseens, Astronomisch Instituut, BELGIUM

Ecole Royede Milituire, Lob. de Phy. Plaemas, BELGIUM

Commiscion-Europeen, DG. XII-Fusion Prog., BELGIUM

Prof. A. Bouciqub, Rijkeuniveribit Gent, BELGIUM

Dr. P.H. Sakanaka, Instituto Firica, BRAZIL

Inetiuto Neciond Do Pecquians Espadidi-INPE, BRAZIL

Documents Orifice, Acomic Energy of Cenada Lid., CANADA

Dr. M.P. Bectyynak, MPB Technologies, Inc., CANADA

Dr. H.M. Skaregard, Univ. of Sackatchewen, CANADA

Prof. J. Toichmann, Univ, of Montreal, CANADA

Prof. S.R. Sreenivesen, Univ. of Calgary, CANADA

Prof. T.W. Johnston, INRS-Energio, CANADA

Dr. R. Botton, Centre canadien de fusion magnótique, CANADA

Dr. C.R. James, Univ. of Nberta, CANADA

Dr. P. Luktec, Komensketho Universzita, CZECHOSLOVAKIA

The Librarian, Culhem Laboratory, ENGLAND

Library, R61, Ruthertord Appleton Laboratory, ENGLAND

Mrs. S.A. Hutchineon, JET Librery, ENGLAND

Dr. S.C. Sherme, Univ. of South Pacific, FIJI ISLAINDS

P. Mathonen, Univ. of Helsinki, FINLAND

Prof. M.N. Buseac, Ecole Polytectinique, FRANCE

C. Moutter, Lab. de Physique des Milioux lonisés, FRANCE

J. Radet, CENCADARACHE - Bat 506, FRANCE

Prof. E. Economou, Univ. of Crete, GREECE

Mi. C. Rinni, Univ. of loannina, GREECE

Dr. T. Mued, Acadermy Bibliographic Ser., HONG KONG

Proprint Librery, Hunoarian Acadomy of SA., HUNGARY

Dr. B. DasGupta, Saha Inst of Nuciear Physics, INDIA

Dr. P. Kaw, Inst. for Plasma Rosearch, INDIA

Dr. P. Rosenau, leraed inst of Technology, ISPAEL Librarien, Intomational Conter for Theo Physics, ITALY Miss C. De Palo, Associazione EURATOMENEA, ITALY Dr. G. Grosso, Istituto di Fisica del Plasma, ITALY

Prof. G. Rostangni, Istituto Gas lonizzati Dol Cnr, ITALY

Dr. H. Yamato, Tochiba Ros Devel Centor, JAPAN
Prof. I. Kawakami, Hroshima Univ., JAPAN

Prot. K. Nishikawa, Hiroshima Univ., JAPAN

Director, Japan Alomic Enorgy Research Inst, JAPAN

Prot. S. ioh, Kyushu Univ., JAPAN

Research Into. Ctr., National Instit. for Fusion Science, JAPAN

Prof. S. Tenaka, Kyoto Univ., JAPAN

Librery, Kyoto Univ., JAPAN

Prot. N. Inowe, Univ. of Tokyo, JAPAN

Secretary, Plesma Section, Electrotechnical Lab., JAPAN

S. Mori, Tectnical Advieor, LAERI, JAPAN

Dr. O. Miterd, Kumamoso Inst. of Technology, JAPAN

J. Ayeon-Sook, Korva Alomic Enorgy Research Inst, KOREA

D.I. Choi, The Korea Adv. Inst. of Sai. \& Tech, KOREA

Prof. B.S. Liloy, Univ. of Waikato, NEW ZEALAND

Inst of Physics, Chinese Acad ScA PEOPLE'S REP. OF CHINA

Library, Inst of Plasma Physics, PEOPLE'S REP. OF CHINA

Tsinghua Univ. Library, PEOPLE'S REPUBLIC OF CHINA

Z. L, S.W. Inst Phyeics, PEOPLE'S REPUBLC OF CHINA

Prof. J.A.C. Cebral, Instituto Superior Tecnico, PORTUGAL

Dr. O. Potrus, AL I CUzA Univ., ROMaNIA

Dr. J. do Villiers, Fucion Studies, AEC, S. AFRICA

Prof. M.A. Hewberg, Univ, of Natal, S. AFRICA

Prot. D.E. Kim, Pohang Inat. of Soi. \& Tech., SO. KOAEA

Prof. C.I.E.M.A.T, Fusion Dtrision Library, SPAIN

Dr. L Stenfio, Univ. of UMEA, SWEDEN

Libray, Royed Inst. of Tectnology, SWEDEN

Prot. H. Wilholmson, Chaimers Univ. of Tech, SWEDEN

Contro Phys Dos Plaemas, Ecolo Polytech, SWITZERLAND

Bibliotheok, Inat. Voor Plasma-Fysica, THE NETHERLANDS

Asst. Prot. Dr. S. Cokir, Middo East Tech. Univ., TURKEY

Dr. V.A. Gukhikh, Sai. Res. Inst. Electrophys.I Apparatus, USSR

Dr. D.D. Ayutov, Siberian Brench of Academy of Sa., USSR

Dr. G.A. Eliseev, I.V. Kurchatov Inst, USSR

Librarien, The Ukr.SSR Academy of Sciences, USSR

Dr. LM. Kovriztnnykh, Inst. of General Physias, USSA

Komforsctingsankage GmbH, Zentralbibliothek, W. GERMANY

Bibliothek, Inst. For Plasmatorschung, W. GERMANY

Prof. K. Schindler, Ruhr-Universitát Bochum, W. GERMANY

Dr. F. Wagner, (ASDEX), Max-Planck-Institut, W. GERMANY

Librerian, Max-Plenck-Institur, W. GERMANY

Prof. R.K. Janov, Inst of Physics, YUGOSLAVIA 

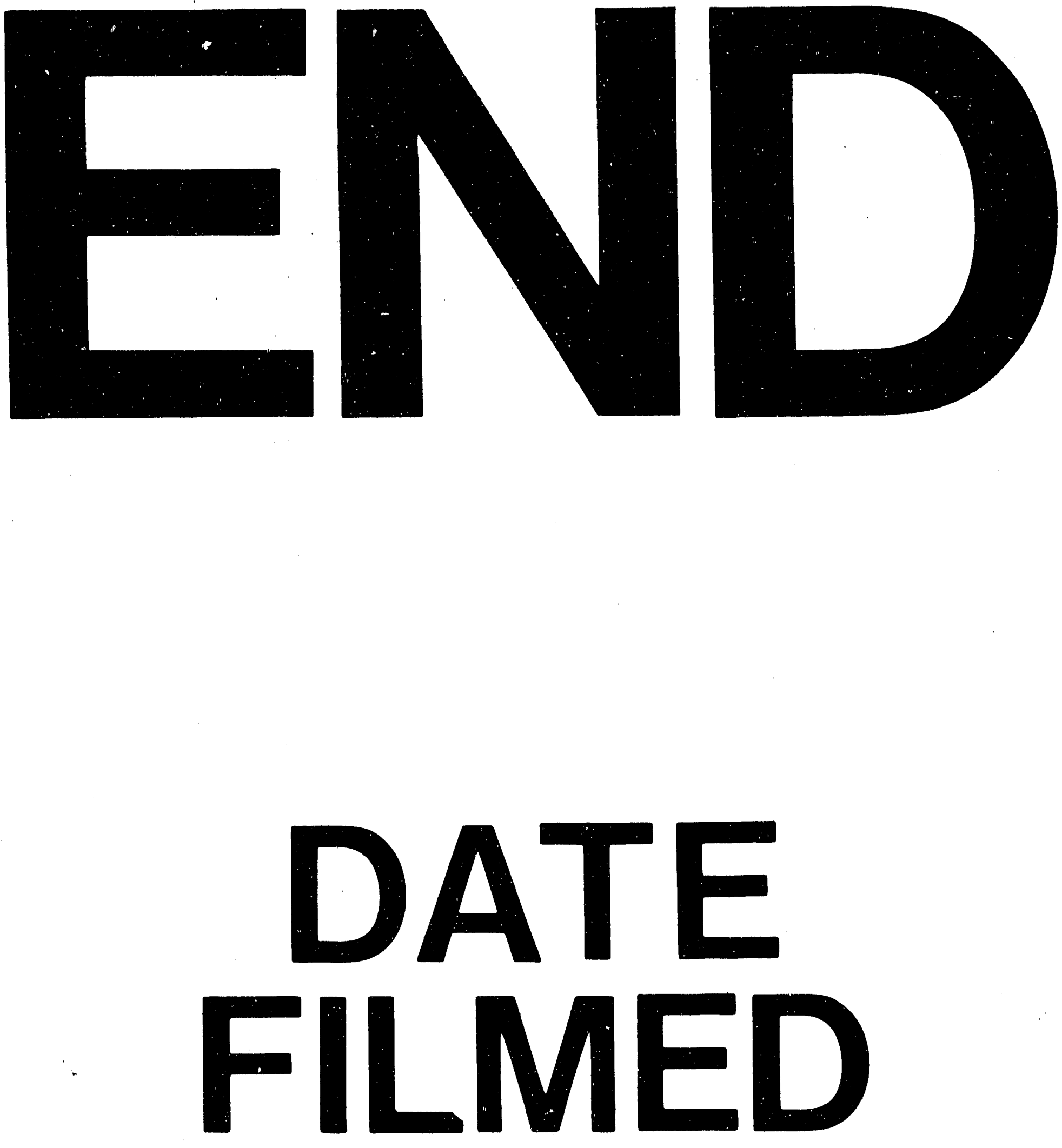

I

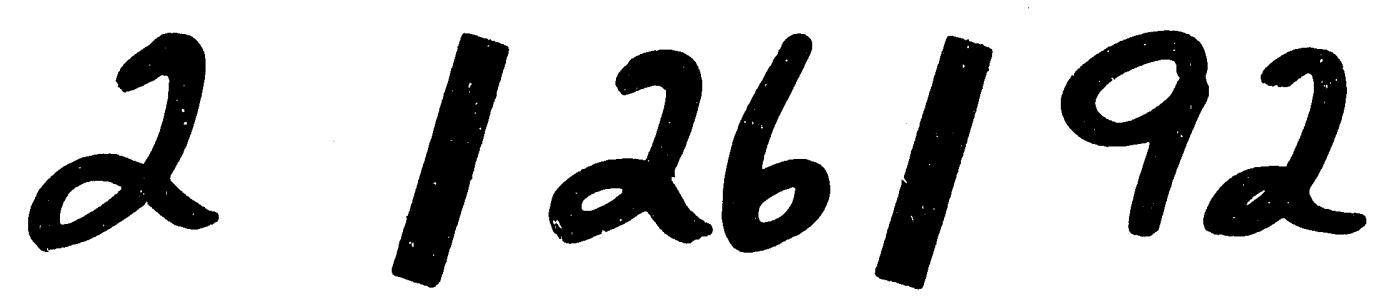


